\title{
Case study on the environmental impact and efficiency of travel
}

\author{
Evelyn Otero ${ }^{1}\left[\right.$ Ulf Ringertz $^{1}$
}

Received: 18 June 2021 / Revised: 18 June 2021 / Accepted: 23 August 2021 / Published online: 22 September 2021

(c) The Author(s) 2021

\begin{abstract}
Traveling and possible impact on climate and environment are currently under intense debate, and air travel in particular is often in question due to the use of fossil fuels. Electric propulsion has therefore become very popular but the energy sources for electricity generation should as well be taken into consideration. On the other hand, the social aspect of traveling is usually forgotten and should be also included for a complete sustainability analysis. In this study, the business trip from Stockholm to Bordeaux experienced by airplane and train is analyzed. Though the journey by airplane generated six and a half times more $\mathrm{CO}_{2}$ emissions than the journey by train on a per-passenger basis, this latter resulted in a 35-h journey compared to seven, and a cost up to eight and a half times more expensive than the airplane. The trip is defined as an optimization problem with focus on environmental, economic, and social impact to define acceptable trade-offs. The critical criteria for transportation mode choice were identified as the environment, time and comfort, and a value model for business travel mode optimization is proposed, integrating as well a personal value.
\end{abstract}

Keywords Environmental impact · Gas emissions · Energy sources · Travel efficiency · Transportation modes · Sustainability

\section{Introduction}

Transportation modes have strongly evolved and expanded over the last decades resulting in an increase of personal and also professional traveling. This phenomenon has led to an intense debate about the environmental impact caused by traveling, mainly due to the use of fossil fuels and the associated emissions. Air travel is perhaps most in question and is also analyzed in detail [1-4]. It is at the same time one of the most challenging modes of transport towards sustainability and in particular for long-distance travel. But it all comes down to the way the energy is generated. Electric propulsion [5] is for example very popular due to its apparent cleanliness, but how electrical power is generated is not so much debated and this is crucial for a fair comparison of the different modes of transportation.

Universities [6-8] are as well concerned by the impact of their business traveling and the Royal Institute of Technology (KTH) has recently introduced an internal tax [9] on

Evelyn Otero

otero@kth.se

1 Department of Engineering Mechanics, Royal Institute of Technology (KTH), SE-100 44 Stockholm, Sweden air travel motivated by a desire to reduce the carbon dioxide footprint from air travel. On the other hand, other means of transportation are currently not considered for this type of internal tax. Current regulations at KTH for travel [10] state that all business trips should minimize environmental impact and cost but still with reasonable travel time. It is also stated that traveling should always be as safe as possible and promote work efficiency. Consequently, in order for a KTH employee to perform a business trip, optimization should consider:

1. Environmental impact.

2. Safety.

3. Work environment.

4. Time.

5. Cost.

This is, however, not an easy optimization problem to solve since these objectives are in many ways in conflict with each other. For example, how much extra time and cost are acceptable to reduce environmental impact?

Very few are the papers which investigate business travel modes [6-8] and none of them compare transportation modes by considering the environmental, economic 
and social aspect which are the three pillars of sustainability [11] which should be balanced. The aim with this study is to assess the overall impact of business travel modes in terms of the mentioned criteria on environmental, economic and social sustainability in order to make optimal choices. For that, a comparison between two means of transportation is carried out, namely the airplane and the train, based on a real case scenario. The route analyzed corresponds to the business trip from Stockholm, Sweden to Bordeaux, France, Fig. 1. The analysis is based on data retrieved from the experienced trip, and completed by available data sources. Different models for the energy and emissions computations have been defined depending on the transportation mode considered, namely the train or the airplane. For the case of the emissions computation of aircraft trajectory, a well-known model has been used, the Boeing Fuel Flow method [12].

This paper starts with a detailed information on the data and methods used for the investigation. Then, a travel comparison is carried out in terms of the environmental impact, safety, work environment, time, and cost, finishing with a discussion on a possible model for optimal business travel mode choice. The discussion also addresses an analysis on transportation energy sources and limitations of the study.

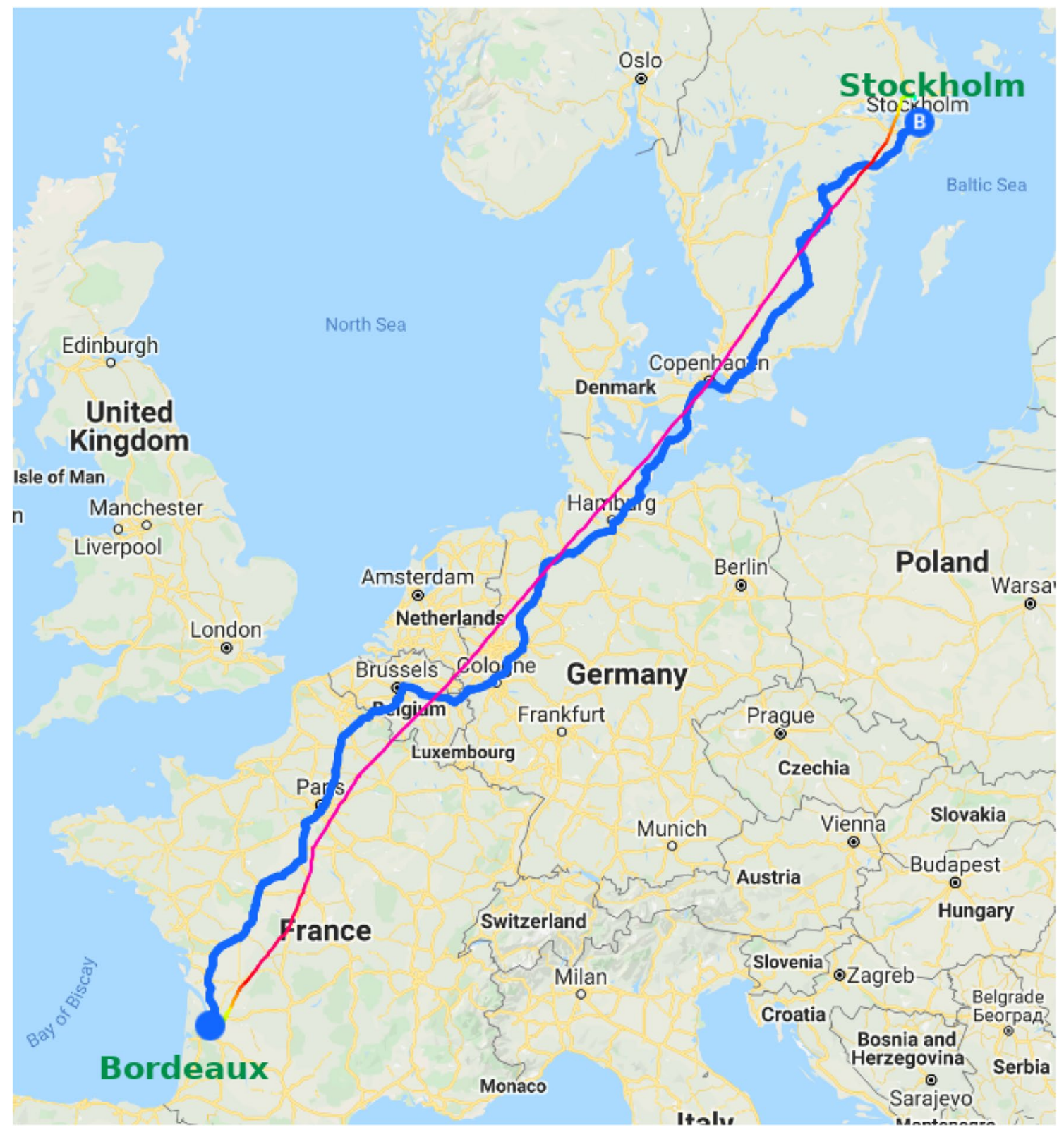

Fig. 1 Travel map by train (blue) and air (red) 


\section{Data and methods}

In this section, the methods and the data used for the analysis of the trip by train and air are presented. For both travel analysis, the noise has been measured with an application installed in a mobile phone [13].

Concerning the energy computation, not only the chemical energy content of the fuel used is estimated, but also the energy required for propulsion. A comparison between the chemical energy content of diesel fuel used and the electrical energy used in for example trains can be misleading since these two types of energy sources are quite different. For a diesel engine, losses are significant $[14,15]$ meaning that only a fraction of the chemical energy content of the fuel is actually used for propulsion. In electrical vehicles, losses in the electrical motor are much smaller [16]. However, the loss of efficiency in electrical propulsion is much more dependent on how the electrical power is generated and distributed. This aspect will be considered in the present investigation.

\subsection{Travel by airplane}

\subsubsection{Data}

The aircraft on this trip is the Boeing 737 which is a turbofan jet aircraft developed in a number of configurations and large numbers. The first flight with the first version, the 737-100, took place in 1967 and the aircraft model has since then been upgraded and refined continuously. The present flight was performed with the 737-800, and the essential characteristics of the aircraft are listed in Table 1.

The analysis is based on a brief pilot report, Sect. 3.1.1, and a transponder track obtained from an on-line flight data monitoring service [17]. Initial aircraft configuration is listed

Table 1 Basic data for the Boeing 737-800

\begin{tabular}{ll}
\hline Dimensions & \\
Length & $39.5 \mathrm{~m}$ \\
Wing span & $34.3 \mathrm{~m}$ \\
Wing reference area $(S)$ & $124.6 \mathrm{~m}^{2}$ \\
Max take-off weight (MTOW) & $79,000 \mathrm{~kg}$ \\
Max fuel load & 26,0001 \\
Crew (pilots and cabin crew) & 6 \\
Passengers (pax) & max. 189 \\
Engine performance (CFM56-7B27) & \\
Max thrust & $121.4 \mathrm{kN} / \mathrm{engine}$ \\
Fuel flow at cruise (typical) & $2450 \mathrm{~kg} / \mathrm{h}$ \\
Performance & \\
Max cruise speed & Mach 0.82 \\
Max cruise altitude & 41,000 feet (FL41) \\
\hline
\end{tabular}

in Table 2, and time histories for the flight are shown in Fig. 2. Note that the variation in ground speed is due to the change in wind speed.

Based on these data, the following methods are used to analyze the environmental consequences in terms of energy consumption and emissions.

\subsubsection{Model for energy analysis}

The computation of the energy required for propulsion is based on the following model. In equilibrium, basic performance analysis [18] states that force equilibrium in the direction of flight should satisfy

$T=D+m g \sin \gamma$,

where $T$ denotes total engine thrust, $D$ total drag, $m$ mass of the aircraft, $g$ gravity and $\gamma$ flight path angle. Multiplying this by true airspeed $V$ gives an estimate of the power used as

$P=V D+m g \dot{h}$,

where the climb rate is $\dot{h}=V \sin \gamma$.

Moreover, a simple total drag model is given by

$C_{D}=C_{D 0}+k\left(C_{L}-C_{L}^{*}\right)^{2}$,

where $C_{D}=D /(q S)$ is the non-dimensional drag coefficient and $C_{L}=L /(q S)$ the lift coefficient. The dynamic pressure $q$ is obtained from the true airspeed and the International Standard Atmosphere (ISA) model, see Anderson [18] or Etkin [19] for further details. Estimates for the zero lift drag, lift coefficient for minimum drag, and the induced drag coefficient in Eq. (3) are $C_{D 0}=0.0213, C_{L}{ }^{*}=0.13$ and $k=0.06$. These approximate values are obtained from Obert [20]. With these drag data, it is possible to approximately estimate the power use during the flight as presented in Fig. 3. These results are approximate and should be treated as such.

From the power computation, the energy consumption for propulsion is derived as the integral of the power $T V$ over time,

$E_{\text {prop,air }}=\int T V \mathrm{~d} t$

Table 2 Aircraft configuration for the flight Stockholm/Arlanda (ARN)- Bordeaux (BOD)

\begin{tabular}{ll}
\hline Gross weight & $64,270 \mathrm{~kg}$ \\
Initial fuel load & $10,870 \mathrm{~kg}$ \\
Crew & 6 \\
Passengers (pax) & 125 \\
Temperature & ISA+6 \\
Wind at cruise altitude & $208 \mathrm{deg} / 46$ knots \\
\hline
\end{tabular}


Fig. 2 Altitude (left) and ground speed (right) for the flight Stockholm/Arlanda (ARN)-Bordeaux (BOD). Data source from on-line service [17]
Fig. 3 Total power use and power use per passenger for propulsion
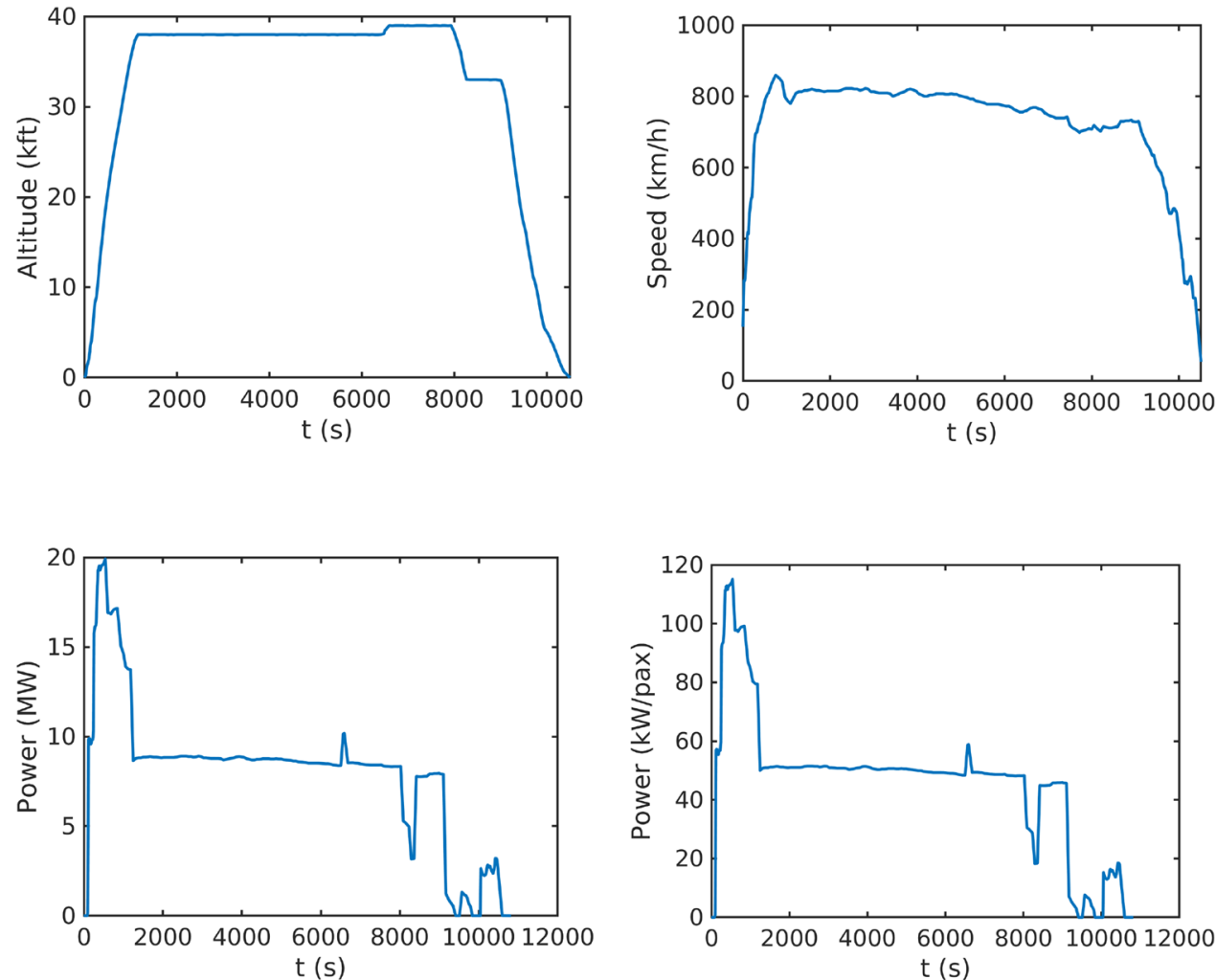

Furthermore, the total energy consumed by the airplane based on the total fuel consumed is computed in terms of the chemical energy content of the fuel as

$E_{\mathrm{tot}, \mathrm{air}}=E_{\mathrm{cf}} f_{b, \mathrm{tot}}$,

where $E_{\mathrm{cf}}$ is the energy content of the fuel JET-A1 which is $43 \mathrm{MJ} / \mathrm{kg}$, and $f_{b, \text { tot }}$ the total fuel burned in $\mathrm{kg}$.

These two types of energies, for propulsion $E_{\text {prop,air }}$ and the total energy $E_{\text {tot,air }}$, will give the energy efficiency of the fossil jet fuel in percentage with respect to the total energy consumed $\left(E_{\text {prop,air }} / E_{\text {tot,air }}\right)$.

\subsubsection{Emissions modelling}

The engine exhaust emissions considered in this study are carbon dioxide $\left(\mathrm{CO}_{2}\right)$, carbon monoxide $(\mathrm{CO})$, hydrocarbons $(\mathrm{HC})$, nitrogen oxides $\left(\mathrm{NO}_{x}\right)$, sulfur oxides $\left(\mathrm{SO}_{x}\right)$, and also water vapor $\left(\mathrm{H}_{2} \mathrm{O}\right)$. The emissions modeling is based on the emission indexes (EI) which correspond to the emission in grams per kilogram of fuel consumed. Depending on the type of the emission, a more or less complex model may be required.

In the case of $\mathrm{CO}_{2}, \mathrm{H}_{2} \mathrm{O}$, and $\mathrm{SO}_{x}$ emissions, these are modeled based on jet fuel composition [21] using Boeing-derived emissions indices [22]. These emissions are therefore proportional to the fuel burn with constant emission indices as follows

$$
\begin{aligned}
E I C O_{2} & =3155 \mathrm{~g} /(\mathrm{kg} \text { fuel }) \\
E^{2} H_{2} O & =1237 \mathrm{~g} /(\mathrm{kg} \text { fuel }) \\
E^{2} O_{x} & =0.8 \mathrm{~g} /(\mathrm{kg} \text { fuel }) .
\end{aligned}
$$

On the other hand, the computation of the remaining emission indices requires a more complex model and in this study the fuel flow method $2[23,24]$ is used. This model relies on readily available data such as the engine fuel flow, $f_{\text {alt }}$, provided by the BADA database $[25,26]$ at altitude level, and which then needs to be corrected to a corresponding fuel flow at sea level, $f_{\mathrm{sl}}$. However, in this study, the trajectory is not simulated and the fuel flow $f_{\text {alt }}$ at a given time is directly extracted from Flight Data Recorder (FDR) data. A model of the sea-level emission indices as function of the fuel flow at sea level is also required represented here by $E I C O_{\mathrm{sl}}, E I H C_{\mathrm{sl}}$, and $E I N O_{x_{\mathrm{sl}}}$ using the four certification data points from the International Civil Aviation Organization (ICAO) emissions databank [27] and the APEX data [28] with more detailed measurements on a similar engine. These emissions data points are measured at sea level at different thrust levels and can be correlated to different fuel burn levels. The method for using the four data points is presented in [24]. The corresponding emission indices corrected for altitude and computed for different points during the flight trajectory read 


$$
\begin{aligned}
& E I C O_{\text {alt }}=E I C O_{\mathrm{sl}}\left(f_{\mathrm{sl}}\right) \frac{\theta^{3.3}}{\delta^{1.02}} \\
& E I H C_{\mathrm{alt}}=E I H C_{\mathrm{sl}}\left(f_{\mathrm{sl}}\right) \frac{\theta^{3.3}}{\delta^{1.02}} \\
& E I N O_{x_{\text {alt }}}=E I N O_{x_{\mathrm{sl}}}\left(f_{\mathrm{sl}}\right) \sqrt{\frac{\delta^{1.02}}{\theta^{3.3}}} e^{H}
\end{aligned}
$$

with $H$ a humidity correction factor [23, 29], $f_{\mathrm{sl}}$ the corrected fuel flow at sea level,

$f_{\mathrm{sl}}=f_{\mathrm{alt}} \frac{\theta^{3.8}}{\delta} e^{0.2 M^{2}}$,

and $f_{\text {alt }}$ the engine fuel flow at altitude level. Moreover $M$ is the Mach number, $\theta=T / T_{0}$ and $\delta=P / P_{0}$, where $T$ is the temperature in Kelvin, $P$ the pressure in $\mathrm{Pa}$, and the corresponding constants at sea level are $T_{0}=288.15 \mathrm{~K}$ and $P_{0}=$ $101,325 \mathrm{~Pa}$. Note that the Mach number information is also provided in the FDR data, and that the ISA model has been used to compute the temperature and pressure at a given altitude.

Figure 4 illustrates the Boeing fuel flow method with its three phases corresponding to Eqs. (6)-(9), where in this study the fuel flow has been directly taken from FDR data instead of the BADA database as previously mentioned.

Finally, based on the emission indices computed at different times during the whole trajectory (Eqs. (6)-(8)), the total emission during flight is computed in kilograms for each of the gas emissions. Taking $\mathrm{HC}$ as an example this gives

$H C=\frac{1}{1000} \int_{t=0}^{t_{\mathrm{f}}}\left(E I H C_{\text {alt }} f_{\text {alt }}\right) \mathrm{d} t$.

The factor $1 / 1000$ is applied since the emission index is defined in grams per kilogram of fuel consumed.

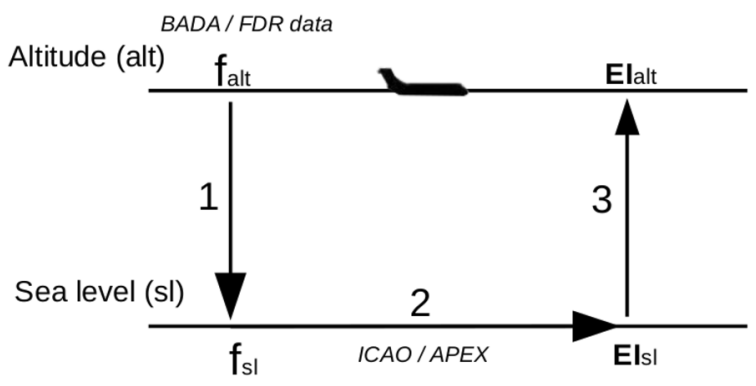

Fig. 4 Procedure of the Boeing fuel flow method (with FDR data used in this study)

\subsection{Travel by train}

In this section, all the transportation modes included in the train journey are considered, namely the different types of trains but also the buses and the ferry. Moreover by journey segment, it is meant the part of the journey covered by a single transportation mode.

\subsubsection{Data}

The computations have been based on available technical data regarding the energy per kilometer and the number of seats for the different types of trains taken [30-36] and also for the additional bus [37]. Data on $\mathrm{CO}_{2}$ emissions from electricity generation per country are also supplied in [38]. Moreover, information has been sometimes provided by the controllers and bus drivers regarding the number of passengers and the fuel consumed.

In addition to that, in order to keep the best possible track of the data related to the whole journey, photos have been taken of the trains used on each segment of the journey. The departure and arrival times have been recorded and also any observation relevant to this investigation, such as delays, number of passengers, and personal impressions.

The number of passengers per journey segment has been one of the most uncertain variables to determine due to the many passengers embarking and disembarking at each station. The number of passengers was estimated using directly the number of tickets sold when provided by the controller, or otherwise based on personal observations of the percentage of occupied seats. More precisely, if for example the train would look like half empty during the whole journey segment, $50 \%$ of the total number of seats would be considered as the number of passengers. Whereas the first method does not take into account the flow variation, it is based on real practical information. A comparison has been carried out using the recommended standardized payload value for passenger trains of 50\% [39] for all the journey segments, which takes into account passenger flow variation. It has been however observed that this would just result in a small increase of the emissions and therefore the first two methods based on the real experience have been used for this analysis.

\subsubsection{Method for energy computation}

The computation of the total energy required for the complete train journey has been divided in to journey segments based on the available technical data, Sect. 2.2.1.

For the trains, the energy in kilowatt hour per passenger, required for a given journey segment is computed as 
$E_{\mathrm{pax}, s}=\frac{D_{s} E_{\mathrm{D}}}{N_{s}}$,

with $D_{s}$ the distance in kilometer measured for the journey segment $s, E_{\mathrm{D}}$ the energy consumed per kilometer for this type of train, in $\mathrm{kWh} / \mathrm{km}$, and $N_{s}$ the estimated number of passengers in this journey segment.

In the case of the diesel trains and buses, the energy is computed using

$E_{\mathrm{pax}, s}=\frac{D_{s} L_{\mathrm{D}} E_{\mathrm{L}}}{N_{s}}$,

and if the fuel burn is provided by the driver, the expression

$E_{\text {pax }, s}=\frac{L_{s} E_{\mathrm{L}}}{N_{s}}$,

can directly be used. $L_{\mathrm{D}}$ represents the liters of diesel consumed per kilometer in $\mathrm{L} / \mathrm{km}$, where $L_{\mathrm{D}}=0.96$ for the train, and $L_{\mathrm{D}}=0.4$ for the bus. Moreover $L_{s}$ corresponds to the liters of diesel consumed for the given journey segment, provided by the driver, and $E_{\mathrm{L}}=9.6$ is the energy contained in a liter of diesel in $\mathrm{kWh} / \mathrm{L}$.

The total energy per passenger can be then computed as the sum of all the energies consumed on each journey segment as

$E_{\mathrm{pax}, \mathrm{tot}}=\sum_{s=1}^{n} E_{\mathrm{pax}, s}$,

with $n$ representing the number of journey segments.

For the corresponding energy required for propulsion, the same energy values are used for the electric trains due to their high energy efficiency with over $90 \%$ [16] of the total energy used for propulsion. However for the diesel trains and buses, an approximate energy efficiency of $30 \%[14,15]$ is applied to the total energy consumed.

\subsubsection{Method for emissions computation}

For the train journey analysis, only the $\mathrm{CO}_{2}$ emissions are considered due to the limitation of available data sources related to the other gas emissions. Two different methods have also been used to compute the emissions, depending on the type of energy source, namely electricity or fossil fuel.

For the electric trains, the $\mathrm{CO}_{2}$ emissions in grams per journey segment, country and passenger are computed as follows

$C O_{2_{\mathrm{pax}, s / c}}=\frac{D_{s / c} E_{\mathrm{D}}}{N_{s}} C O_{2_{\mathrm{E}, c}}$,

with $D_{s / c}$ the distance in $\mathrm{km}$ measured for the journey segment $s$ in a country $c$. Furthermore, $\mathrm{CO}_{2 \mathrm{E} c}$ corresponds to the grams of $\mathrm{CO}_{2}$ emissions per $1 \mathrm{kWh}$ of energy generated in the given country [38], in $\mathrm{g} / \mathrm{kWh}$. The $\mathrm{CO}_{2}$ emissions per journey segment over different countries is then computed as the sum of the emissions for the corresponding journey subsegments per country $s / c$.

For the diesel trains and buses, the corresponding $\mathrm{CO}_{2}$ emissions intensity reads as in Eq. (16) or Eq. (17) if the fuel consumption is provided by the driver.

$C O_{2_{\mathrm{pax}, s}}=\frac{D_{s} L_{\mathrm{D}} C O_{2_{\mathrm{L}}}}{N_{s}}$

$C O_{2_{\mathrm{pax}, s}}=\frac{L C O_{2_{\mathrm{L}}}}{N_{s}}$.

with the constant $\mathrm{CO}_{2 \mathrm{~L}}=2640 \mathrm{~g} / \mathrm{L}$, the $\mathrm{CO}_{2}$ emissions in grams per liter of diesel consumed.

\subsection{System boundaries}

The travel investigation is limited to the journey between the railway stations and airports of origin and destination. The transportation from and to the airport or train station has been excluded since this aspect can strongly vary depending on the traveler's home location and his or her final destination. Whereas some conferences may be held close to the airports for example, other may be closer to the train stations. The same applies to the home location.

Moreover, the investigation only focuses on two transportation modes, the airplane and train since these are considered to be the most optimal air and land transportation modes, respectively, for a business journey of about $2000 \mathrm{~km}$, compared to for example taking the car, bus or even boat.

Concerning the emissions calculation, the delimitation of the study is linked to the limitations presented in Sect. 4.4. Whereas $\mathrm{CO}_{2}$ and non- $\mathrm{CO}_{2}$ emissions are computed for the journey by airplane based on real data, the comparison with respect to the train is only based on $\mathrm{CO}_{2}$ emissions for a direct comparison, due to the lack of information on other non- $\mathrm{CO}_{2}$ emissions from electricity generation per country. For the electricity source, grid transmission and distribution losses have not been accounted.

Finally noise analysis is only carried out inside the transportation mode and no external noise is assessed. The energy consumption is only computed for the transportation mode itself and no additional energy from the airport, railway stations or even hotel [40] is included. 


\section{Travel analysis}

\subsection{Personal travel experience}

\subsubsection{By airplane}

The travel by air was a direct flight from Stockholm to Bordeaux, Fig. 1, in a Boeing 737-800 (Table 1) with 125 passengers, not completely full since the maximum seating capacity is 189 passengers. The distance was $2063 \mathrm{~km}$ between both airports, namely Arlanda (ARN) and Bordeaux (BOD), with a total fuel burned of about $7182 \mathrm{~kg}$ and $3 \mathrm{~h}$ of flight.

The flight conditions were in general good at all levels, however there was a flight delay of 2 and a half hours. This additional waiting time was compensated by some productive working hours, and the opportunity to speak to the pilot to obtain some additional data on the flight that was relevant to the present investigation.

\subsubsection{By train}

Travel by train was performed for the way back, from Bordeaux to Stockholm with a distance of about $2422 \mathrm{~km}$. This journey included eleven different vehicles namely, eight trains, two buses and one ferry. Moreover the total time spent on the different means of transportation was approximately $27 \mathrm{~h}$.

The train journey experienced at each individual segment gave a positive impression being efficient and comfortable. However from an overall point of view, the whole journey ended up being exhausting due to the many connections. Further, the journey also became very frustrating after a train cancellation with uncertainties on how to reach the final destination and what the impact on the future connections would be. In fact, the train company did not provide a complete replacement of the cancelled train but rather redirected the affected passengers up to a given destination from which one had to figure out how to finalize their journey. This change of plans resulted in an additional bus journey from Belgium to Germany and three more trains loosing the next scheduled connection. But fortunately, the domino effect concluded at the hotel stay at Hamburg, Table 8.

\subsubsection{Comparative analysis}

In order to apply a direct comparison between both travel experiences from a personal point of view, different metrics have been defined on a scale from 1 to 5 (Table 3 ).
Table 3 Evaluation and comparison of personal travel experiences by airplane and train in a scale from 1 (very bad) to 5 (very good) considering the whole journey

\begin{tabular}{lll}
\hline Metrics & By airplane & By train \\
\hline Working conditions & 4 & 4 \\
Waiting time & 2 & 4 \\
Efficiency & 4 & 1 \\
Predictability & 4 & 1 \\
Calmness & 4 & 1 \\
Total & $18 / 25$ & $11 / 25$ \\
\hline
\end{tabular}

Table 3 clearly indicates an overall lack of personal satisfaction with the experienced journey by train compared to the air journey.

\subsection{Environmental impact}

\subsubsection{By airplane}

The total energy consumed during the journey by airplane and the respective energy used for propulsion are given in Table 4 computed as described in Sect. 2.1.2. The total fuel consumed was computed based on data provided by the pilot at the destination airport.

Using the fuel burn, airspeed and altitude for the journey, it is also possible to estimate the gas emissions from the engines during flight, not only affecting the climate but also health, namely $\mathrm{CO}_{2}, \mathrm{H}_{2} \mathrm{O}$ for the possible formation of contrails, $\mathrm{NO}_{x}, \mathrm{HC}, \mathrm{CO}$, and $\mathrm{SO}_{x}$. The emission analysis results, Table 4, were obtained using the procedures developed by Jacobsen [41] which are based on the Boeing fuel flow method [12] as described in Sect. 2.1.3. Emission index data for the engine model CFM56-7B27 is taken from [27].

From Table 4, it can be observed that the $\mathrm{CO}_{2}$ emissions correspond by far, to the largest amount of gas emissions, with about $180 \mathrm{~kg}$ per passenger followed by the $\mathrm{H}_{2} \mathrm{O}$ with a factor of 2.5. Moreover one can also observe the low efficiency of the fossil fuel of only $30 \%$ and which should be considered for transportation mode comparison.

The $\mathrm{CO}_{2}$ emissions were validated with respect to the information provided in the purchased flight ticket where the ICAO carbon emissions calculator was used [42]. In fact the indicated average $\mathrm{CO}_{2}$ emissions of $165.41 \mathrm{~kg} /$ person were very similar to ours, considering the number of seats occupied at the moment of the purchase and not the final number of passengers as in this study. Moreover the resulting value of $0.088 \mathrm{kgCO}_{2} /$ pax. $\mathrm{km}$ is in accordance as well with other studies [40, 43]. However note that these numbers are very dependent on the number of passengers for the given flight. 
Table 4 Statistics of fuel, energy and emissions for the journey Stockholm-Bordeaux by airplane

\begin{tabular}{|c|c|c|}
\hline \multicolumn{3}{|l|}{ Energy } \\
\hline Total fuel (ARN-BOD) & $7182 \mathrm{~kg}$ & \\
\hline Fuel/pax & $57.5 \mathrm{~kg}$ & \\
\hline Energy content of fuel used & 309 GJ / (85,833 kWh) & \\
\hline Energy for propulsion & 86 GJ / $(23,889$ kWh $)$ & \\
\hline Efficiency & $28 \%$ & \\
\hline Total energy/pax & $2472 \mathrm{MJ} /(687 \mathrm{kWh})$ & \\
\hline Energy for propulsion/pax & $688 \mathrm{MJ} /(191 \mathrm{kWh})$ & \\
\hline Emissions & $\mathrm{kg}$ & $\mathrm{kg} / \mathrm{pax}$ \\
\hline $\mathrm{CO}$ & 36.6 & 0.29 \\
\hline $\mathrm{HC}$ & 1.4 & 0.011 \\
\hline $\mathrm{NO}_{x}$ & 80.7 & 0.64 \\
\hline $\mathrm{CO}_{2}$ & 22659.2 & 181.3 \\
\hline $\mathrm{H}_{2} \mathrm{O}$ & 8884.1 & 71.1 \\
\hline $\mathrm{SO}_{x}$ & 5.7 & 0.05 \\
\hline
\end{tabular}

Moreover, to compare to other means of transportation, it would be necessary to define weights for each of these emissions, focusing more on climate or human health.

\subsubsection{By train}

Table 5 gives the whole itinerary with transportation modes with the corresponding energy consumed and $\mathrm{CO}_{2}$ emissions on Table 6 using the previously presented methods in Sect. 2.2. Figure 5 shows the different levels of grams of $\mathrm{CO}_{2}$ emissions per $1 \mathrm{kWh}$ of energy generated in the country of a given journey segment [38].

The ferry between Puttgarden and Rødby could be neglected for several reasons, namely its new integrated hybrid system [44], its multi-function transportation service with a high capacity in terms of transportations of goods and passengers, and the short distance covered. By looking at the energy required for propulsion, it can be observed that though the power required by a train is about three times smaller than for the airplane, see [45] and Fig. 3, the resulting total energy over time is of the same order of magnitude, of about $191 \mathrm{kWh} / \mathrm{pax}$ for the airplane, Table 4, and of about $132 \mathrm{kWh} /$ pax for the train. However the significant difference comes from the total energy consumed about five times lower per passenger for the train, and from the $\mathrm{CO}_{2}$ emissions almost one order of magnitude lower per passenger for the train journey compared to traveling by air.

Compared to the airplane, and as mentioned earlier in Sect. 2.2.1, the complexity in assessing the number of passengers per train journey segment makes the data inaccurate and perhaps too optimistic. In fact, the number of passengers provided by the controller does not apply to the whole journey since there is a passenger flow movement at each station. However, despite this complexity, our results are in agreement with other studies [40] considering either the whole
Table 5 List of the different journey segments for the route Bordeaux-Stockholm by train (ferry excluded, between segment 7 and 8)

\begin{tabular}{|c|c|c|c|}
\hline$s$ & Transport & Journey segment / Country(ies) & Energy type \\
\hline 1 & TGV & Bordeaux-Haute-Picardie / France & Electricity \\
\hline 2 & TGV & Haute-Picardie-Bruxelles M. / France-Belgium & Electricity \\
\hline 3 & IC & Bruxelles M.-Verviers C. / Belgium & Electricity \\
\hline 4 & Bus & Verviers C.-Aachen / Belgium-Germany & Diesel \\
\hline 5 & Regio & Aachen—Köln Hbf / Germany & Electricity \\
\hline 6 & ICE 4 & Köln Messe-Deutz-Hamburg Hbf / Germany & Electricity \\
\hline 7 & IC3 & Hamburg Hbf—Puttgarden / Germany & Diesel \\
\hline 8 & Bus & Rødby ferry—Copenhagen / Denmark & Diesel \\
\hline 9 & Øresundstoget & Copenhagen-Hässleholm C. / Denmark-Sweden & Electricity \\
\hline 10 & X 2000 & Hässleholm C.—Stockholm / Sweden & Electricity \\
\hline
\end{tabular}

Data based on the experienced journey 
Table 6 Energy consumption (total and for propulsion*) and carbon dioxide emissions for the route Bordeaux-Stockholm by train

\begin{tabular}{llllll}
\hline Segment $s$ and journey & Distance $(\mathrm{km})$ & Energy $(\mathrm{kWh})$ & Energy $(\mathrm{kWh} / \mathrm{pax})$ & $\mathrm{CO}_{2}(\mathrm{~kg})$ & $\mathrm{CO}_{2}(\mathrm{~kg} / \mathrm{pax})$ \\
\hline 1 & 656 & 13120 & 23 & 767.5 & 1.3 \\
2 & 181 & 3620 & 14.5 & 408.4 & 1.6 \\
3 & 125 & 2077.6 & 6.4 & 352.4 & 1.1 \\
4 & 29 & 111.36 & 1.5 & 30.6 & 0.4 \\
5 & 70 & 1158.7 & 5.7 & 510.7 & 2.5 \\
6 & 439 & 8774 & 35.2 & 3867.6 & 15.5 \\
7 & 147 & 1356.9 & 10.5 & 373.1 & 2.9 \\
8 & 160 & 288 & 5.4 & 79.2 & 1.5 \\
9 & 119 & 1456.3 & 4.2 & 63.3 & 0.2 \\
10 & 496 & 5789.5 & 37.4 & 77 & 0.5 \\
Bordeaux-Stockholm & 2422 & 37752.4 & 143.8 & 6529.8 & 27.5 \\
& & $36523^{*}$ & $131.6^{*}$ & & \\
\hline
\end{tabular}

Data based on the experienced journey



Fig. $5 \mathrm{CO}_{2}$ emissions per $1 \mathrm{kWh}$ of energy generated in a given country crossed during the journey by train [38] journey or a specific journey segment for a given country and transportation mode.

\subsubsection{Comparative analysis}

Based on the low energy efficiency of the fossil fuel shown in Table 4, where only $30 \%$ of the total energy consumed is used for propulsion, the energy comparison between the airplane and the train will only focus on the propulsion. In this way, we aim to remove the impact of the energy source type on transportation mode comparison. However, the $\mathrm{CO}_{2}$ emissions are computed and compared for the total energy consumed since emissions from the electricity energy source are only produced during its generation.

The emissions and energy consumed presented in Tables 4 and 6 are this time analyzed with respect to the occupancy in Fig. 6, to assess its impact on the comparative study between the train and the airplane. For the journey by train, the energy per passenger for a given occupancy percentage has been computed using Eqs. (11)-(14) where the same occupancy percentage has been applied for each journey segment.

As expected, Fig. 6 clearly shows that in both cases there is a strong impact of the number of passengers on
Fig. 6 Comparison of $\mathrm{CO}_{2}$ emissions and energy consumption for propulsion per passenger with respect to the number of passengers
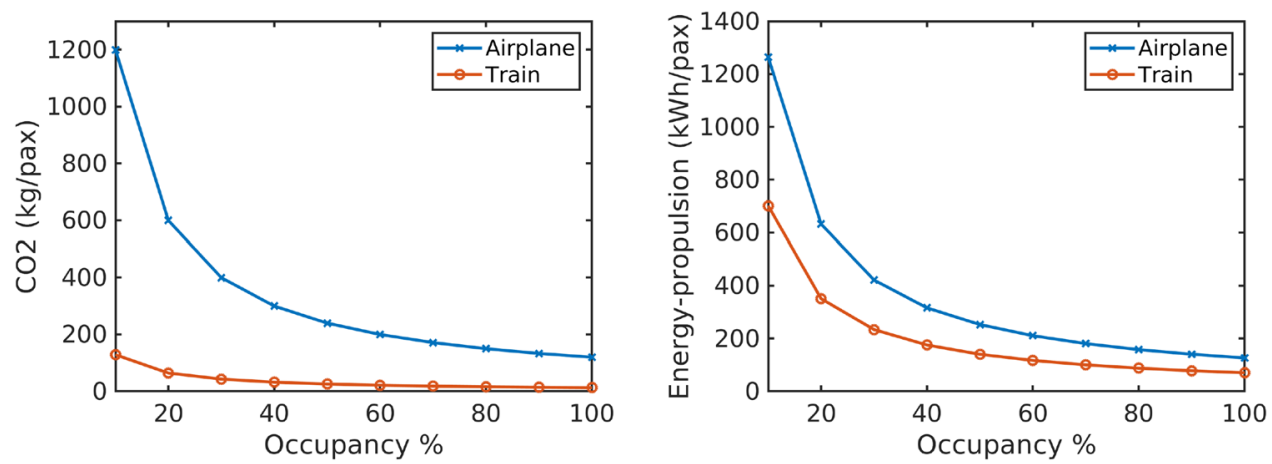
the resulting emissions and energy consumption per passenger, specially for the airplane where an occupancy of $30 \%$ results in $400 \mathrm{kgCO}_{2} /$ pax, Fig. 6 (left), one order of magnitude higher than for the train. Lower capacity usages than that result for the airplane in a dramatic increase of the emissions up to $1200 \mathrm{kgCO}_{2} /$ pax for a $10 \%$ occupancy. It can be observed that a train with a $10 \%$ occupancy is equivalent to a full airplane in terms of $\mathrm{CO}_{2}$ emissions per passenger.

A similar trend can be observed for the energy consumption for propulsion, Fig. 6 (right), but with a much smaller ratio between the airplane and train since the main factor degrading the level of sustainability of the airplane is not accounted anymore, namely the $70 \%$ of additional energy required for the combustion process of the fossil fuel. For an occupancy of $30 \%$, the energy consumption is of about $420 \mathrm{kWh} /$ pax and $230 \mathrm{kWh} /$ pax for the airplane and train, respectively, leading to a ratio of only about two between both cases, instead of 10 as obtained for the $\mathrm{CO}_{2}$ emissions.

This last observation reveals the impact of another major factor behind the environmental impact, namely the type of energy source used for a given transportation mode.

Figure 7 compares the $\mathrm{CO}_{2}$ emissions from the original journey by airplane with three other hypothetical cases

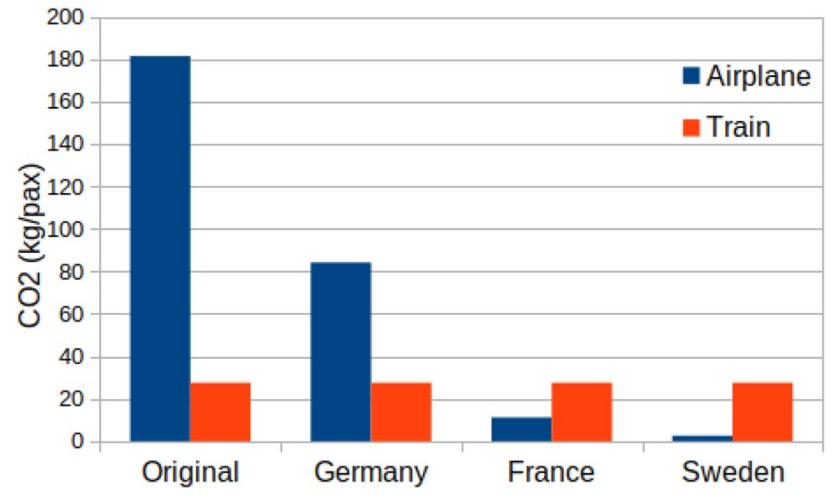

Fig. $7 \mathrm{CO}_{2}$ emissions per passenger by airplane and train. First case: original journey, three other cases: hypothetical fully electric airplane with different countries for electricity generation where the same journey would have been experienced with a fully electric airplane. The four journeys by air are therefore assumed to be identical in terms of distance travelled, energy consumed for propulsion with an occupancy of 125 passengers. The three new cases differ from the country of origin for electricity production namely, Germany, France, and Sweden leading to different levels of $\mathrm{CO}_{2}$ emissions [38], Fig. 5. The $\mathrm{CO}_{2}$ emissions from the journey by air dramatically decrease by replacing the energy source from fossil fuel to electricity, reaching a reduction factor of up to about 71 with electricity generated in Sweden. This also gives a level of $\mathrm{CO}_{2}$ emissions with the electric airplane much lower than for the current journey by train, up to one order of magnitude lower. It can also be observed that though electricity production in Germany generates almost twice the grams of $\mathrm{CO}_{2}$ emissions per $1 \mathrm{kWh}$ compared to the fossil fuel, namely $440.8 \mathrm{gCO}_{2} / \mathrm{kWh}$ (Fig. 5) and 264 $\mathrm{gCO}_{2} / \mathrm{kWh}$ (Table 4 ), respectively, the corresponding total $\mathrm{CO}_{2}$ emissions per passenger are half as high as for the conventional airplane due to the fossil fuel inefficiency requiring additional energy for the combustion process (Sect. 3.2.1).

Hence Fig. 7 not only reveals the impact on the environment of the type of energy used, but also of the type of energy generation, such as coal power mostly used in Germany or hydropower and nuclear power in Sweden, Sect. 4.3.

In Fig. 8, the $\mathrm{CO}_{2}$ emissions and energy consumed from Table 6 for the journey by train, are shown in a cumulative way with respect to the distance travelled and therefore also with respect to the country of energy generation. Each circle in the curve marks the beginning of a journey segment number, from 1 at a distance travelled of $0 \mathrm{~km}$ up to 10 as indicated in Tables 5 and 6 .

In Fig. 8 (left), the high slope increase marked by the gray area from the journey segment number 2 up to 8 (Table 6) corresponds to the countries with the highest $\mathrm{CO}_{2}$ emissions per $1 \mathrm{kWh}$ of electricity produced, namely Belgium and Germany with $169.6 \mathrm{gCO}_{2} / \mathrm{kWh}$ and $440.8 \mathrm{gCO}_{2} / \mathrm{kWh}$ [38] (Fig. 5), respectively. The red dashed line simulates an hypothetical optimal scenario where the same journey is
Fig. 8 Cumulative $\mathrm{CO}_{2}$ emissions (left) and energy consumption for propulsion (right) per passenger with respect to the distance travelled for the train journey. Dashed lines: hypothetical optimal scenarios
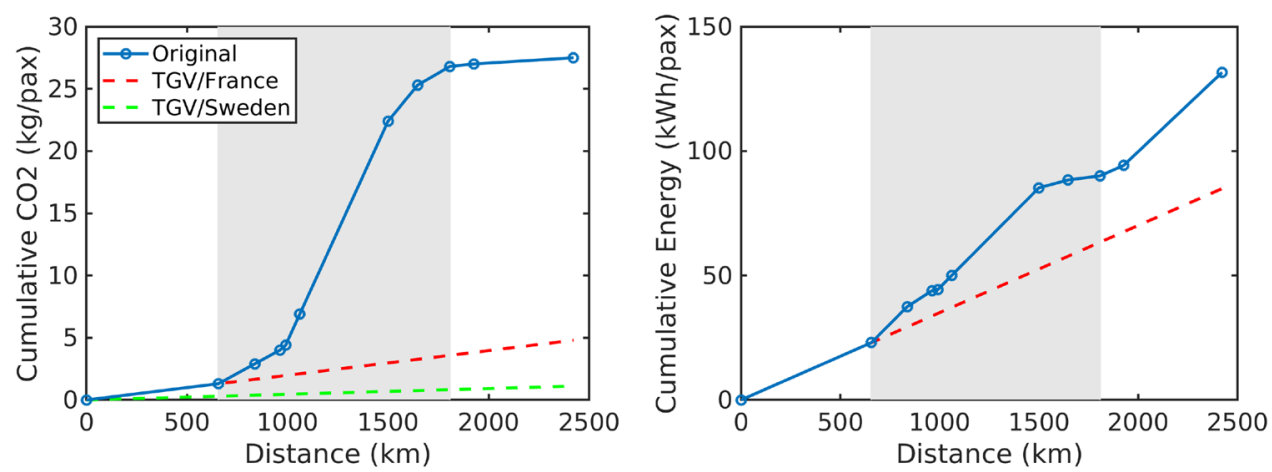
experienced uniquely by TGV and electrical energy from the same country of departure, namely France which has a relatively low $\mathrm{CO}_{2}$ emissions with $58.5 \mathrm{gCO}_{2} / \mathrm{kWh}$ [38], Fig. 5 . This red line clearly marks the huge impact of the energy generation type during the whole journey, and leading to a $\mathrm{CO}_{2}$ emissions decrease by a factor of about 6 compared to the original journey. Considering the energy generation at another country such as Sweden (see green dashed line) with an even lower $\mathrm{CO}_{2}$ emission intensity per $\mathrm{kWh}$ of electricity generated, namely $13.3 \mathrm{gCO}_{2} / \mathrm{kWh}$ [38] (Fig. 5), the emission reduction would be even higher by a factor of 25 .

On the other hand, the cumulative energy, Fig. 8 (right), does not show this disruption through the gray area but rather follows a nearly linear increase. The red dashed line is once again an equivalent journey to the original one but assuming that the same type of train is used during the whole journey, namely the TGV taken at the departure in France, Table 5. One can also observe here a decrease in total energy consumption with an optimal journey by TGV, but with a much lower reduction factor compared to the emissions, namely of 1.7. This difference in energy consumption is due to the additional transportation modes used in the original journey such as older train models less energy efficient. This last point reveals again the weak impact of the type of transportation mode on the environmental impact, not only compared to the energy source type, but also to the energy generation type, Sect. 4.3.

\subsection{Safety}

Safety statistics compiled from United Kingdom government agency studies [46] for the period 1990-2000 are listed in Table 7 with data added for space travel $[47,48]$ and historical aviation. The table gives the number of fatalities for 1 billion journeys, hours and passenger-kilometers, respectively. The data make different conclusions possible depending on

Table 7 Number of fatalities by different means of transportation, for 1 billion journeys, hours and passenger-kilometers [46]

\begin{tabular}{llll}
\hline \multirow{2}{*}{ Type } & \multicolumn{2}{l}{ Fatalities per billion } & \\
\cline { 2 - 4 } & Journeys & Hours & pax.km \\
\hline Bus & 4.3 & 11.1 & 0.4 \\
Train & 20 & 30 & 0.6 \\
Car & 40 & 130 & 3.1 \\
Walking & 40 & 220 & 54.2 \\
Boat & 90 & 50 & 2.6 \\
Flying & 117 & 30.8 & 0.05 \\
Bicycle & 170 & 550 & 44.6 \\
Motorcycle & 1640 & 4840 & 108.9 \\
Flying (1929) & & & 625 \\
Space Shuttle & $104,000,000$ & 442,000 & 2.7 \\
\hline
\end{tabular}

whether the data should be compared based on risk per journey, risk per hour in motion or risk per passenger-kilometer. An apparently very dangerous mode of transport, such as the Space Shuttle, gives interesting perspectives on this. This form of traveling appears to be extremely dangerous per journey with two fatal accidents with everyone killed in only 135 launches before the system was retired in 2011. However, with the large distances covered in space travel, the risk per passenger-kilometer appears to be less than walking or riding a bicycle.

The worst year for air travel is considered to be 1929 when the risk was about four orders of magnitude higher than today demonstrating how some aspects of travel have improved over the years. In fact considering the risk per passenger-kilometer, flying is today much safer than taking the train.

In fact, research on the safety record for the Boeing 737800 , shows that since the first flight in 1997, 13 accidents have occurred resulting in 587 fatalities. Moreover there have been almost 5000 deliveries since then and assuming 20,000 flight hours and an average of 150 passengers per travel we obtain the number of fatalities per billion passenger-kilometer of 0.0489 . This number is in agreement with available statistics in Table 7, [46].

\subsection{Work environment}

This part corresponds to the most subjective part of the whole analysis as explained in Sect. 4.2.1, and is presented as such, from a personal point of view based on the experienced trip.

\subsubsection{Airplane}

The journey by air is characterized by its short travel time (Sect. 3.5), and therefore it does not require the best working conditions. However, looking at the complete journey, the time spent at the airport and on the airplane were both efficient moments to work. Actually, the airport provides sockets and tables, and once sitting in the airplane, one can focus on work without almost any interruption and with an acceptable average internal sound of about $71 \mathrm{dbA}$. Moreover, the conditions were convenient despite the small space, and the lack of internet could also be experienced as a positive aspect avoiding additional distractions.

\subsubsection{Train}

The working conditions on the trains were of good quality as well at all levels. Most of the trains provided power outlets and tables and no unpleasant train motions were experienced. Moreover, the average internal sound calculated over the whole journey was of about $61 \mathrm{dbA}$ and therefore 
perfectly acceptable. In addition to that, some trains included some silent areas contributing to the work performance. Concerning the buses included in this journey, the working conditions were of too low quality mainly for the city bus.

However, this convenient work environment at each journey segment by train, did not compensate the long travel time of a 2-day journey and the high number of connections, resulting in a negative impact on the overall productivity.

\subsection{Time and cost}

For the analysis of the time and cost, only the transportation between the final stations and between the airports has been considered. The reason for that, is that the remaining additional transportation modes to and from the airports and train stations depend on the location of the final destinations, such as the home place and the hotel, in this case. And the hotel could be booked either close to the train station or at the airport itself favoring one or the other transportation mode. Moreover both airports provide convenient transportation modes to the city center, such as regular buses and trains.

Table 8 compares the travel time and cost by train and airplane. The travel duration is split into two parts. The first part corresponds to the time spent in transportation modes (including the waiting time between connections) with an additional case for the train where the hotel cost and time have been added. In the second part, the total travel time is reported by adding the initial waiting time necessary before departure.

The travel time spent by train is by far much longer than by airplane by a factor of about 5 and up to 9 , depending if one considers the total journey or only the time spent on transportation, respectively. This reveals the disadvantage of traveling by air where a much longer time margin is required prior to departure, adding almost a couple of hours extra to the total travel time. Moreover, though the direct flight was only $3 \mathrm{~h}$ long, the total travel time was longer than expected due to a flight delay of two and a half hours resulting in a total travel time of $7 \mathrm{~h}$.

Although time is not directly a cost, it does incur additional working hours and depending on your employer's travel policy may or may not be reimbursed in some way. However, a long travel time can also have an unpleasant influence on working conditions.

The total cost of the train journey was about 547 euros including the additional cost of 146 euros for the hotel night, Table 8 . The prices listed are the original ones with no additional cost coming from the train cancellation. Looking at this price, one would expect some compensation in travel time efficiency. This was by far not the case with about 27 and a half hours spent on means of transportation resulting in a total travel time of 35 and a half hours. This strongly contrasts with the airplane with a cost of 65 euros and a $3 \mathrm{~h}$ flight or $7 \mathrm{~h}$ total travel time.

In summary, the travel time by train was up to 9 times longer than by air and the corresponding price of the train was 6 times more expensive than the airplane.

\section{Discussion}

\subsection{Travel comparison}

From the results presented above, there is a clear and significant difference between the traveling by train and airplane, not only in terms of environmental impact but also in terms of social impact mostly due to the travel time and
Table 8 Total travel time and price, for the route StockholmBordeaux by airplane and train

\begin{tabular}{lll}
\hline Transport & Duration & Price (EUR) \\
\hline TGV/ Bordeaux-Haute-Picardie & $04: 06$ & 117.8 \\
TGV/ Haute-Picardie-Bruxelles-Midi & $01: 34$ & 32.7 \\
ICE 2/ Bruxelles M.-Köln Hbf & $01: 53$ & 3.2 \\
EC 6/ Köln-Hamburg & $04: 07$ & 3.2 \\
EC/ Hamburg Hbf-Rødby ferry + bus to Copenhagen & $02: 45$ & 3.2 \\
Øresundstoget/ Copenhagen-Hässleholm C & $01: 25$ & 2.4 \\
x2000/ Hässleholm C-Stockholm & $04: 02$ & 9.5 \\
Global (Interrail Global 3 days) & & 229 \\
Train travel (total) & $20: 00$ & 401 \\
+ connections time & $27: 38$ & 401 \\
$\quad$ + hotel night stay & 35 & 547.4 \\
Direct flight & $03: 00$ & 65 \\
Bordeaux to Stockholm train station & $35: 40$ & 547.4 \\
ARN to BOD airport & $07: 00$ & 65 \\
\hline
\end{tabular}

Data based on the original purchased trip with no additional cost from the experienced trip 
comfort corresponding here mainly to the working conditions. Whereas the $\mathrm{CO}_{2}$ emissions of the train were one order of magnitude smaller than for the airplane, it also implied a travel duration of about $27 \mathrm{~h}, 9$ times longer than for the airplane, and with a comfort level in terms of number of connections not compensating the long travel duration. The comfort level by train is in fact in accordance to the journey segment covered by each of these trains on the whole journey. For an improvement of the overall comfort level, common trains and railway infrastructures over countries should be required to minimize the number of connections, and higher quality conditions specially for night travels should be provided. However, this will also result in more energy consumption and thus more gas emissions.

Concerning the other variables, such as safety and cost, these do not make any big difference for the choice of transportation mode. In fact, the train and airplane are means of transportation which are both safe enough, with the airplane being nowadays ten times safer than the train. Moreover, even though the cost of traveling by train was up to 8.5 times more expensive than by airplane, for a business traveler, it is not that different considering the cost of working time for the time spent traveling.

\subsection{Framework for optimal business travel mode choice}

The results clearly identify the critical criteria for transportation mode choice for business travel, in terms of sustainability. It appears that the whole decision analysis relies on a combined objective function mainly between environment, time, and also comfort, Sect. 4.2.1, where a significant imbalance between environmental and social impact has been identified, Fig. 9. In fact, as previously observed,

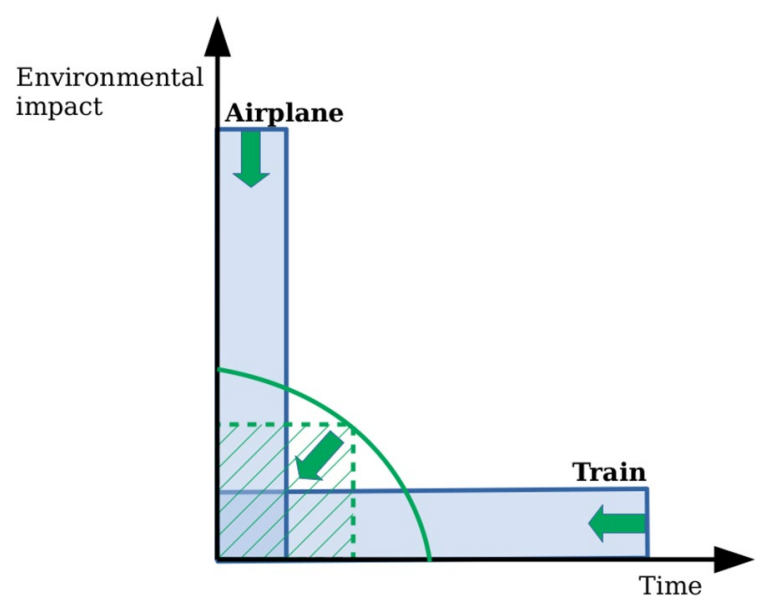

Fig. 9 Illustration of travel impact from an objective perspective, in terms of time and environment for the airplane and train with optimization target (green lines) these variables are generally in conflict with each other. By comfort, here we mean not only the working conditions but also sleeping conditions in case of traveling overnight.

The presented case study has led to the identification of a generic objective function referred here to as travel impact (TI) for a given travel mode option $i, T I_{i}$ (Eq. (19)) based on the whole set of criteria investigated. Note that a travel mode option may imply different types of transportation modes as it was the case for the journey by train. But a travel mode could also be intentionally split into several sub-travel modes, such as by air and land.

This objective function is first developed from an objective perspective, Eq. (19), and therefore excluding the personal criterion of comfort or working conditions. An optimal travel mode (TM) is then identified, $T M_{\text {opt }}$, Eq. (18), considering an appropriate set of travel modes, $S$, for the travel distance considered, such as

$T M_{\mathrm{opt}}: \min _{i \in S} T I_{i}\left(C_{\mathrm{time}, i}, C_{\text {travel }, i}, s_{i}, E_{i}\right)$

and

$T I_{i}=\frac{1}{s_{i}}\left(E_{i} C_{\text {time }, i}+C_{\text {travel }, i}\right)$

with $T I_{i}$ the impact of the business journey using the travel mode $i, C_{\text {travel, } i}$ the total direct cost of the journey including transportation and hotel, and $C_{\text {time }, i}$ the cost caused by the travel time in terms of working hours cost, between the stations or airports of origin and destination including the minimum time required prior to the departure and connections time, excluding the hotel stay. Moreover, $s_{i}$ and $E_{i}$ are safety and emissions coefficients, respectively. $s_{i}$ is defined on a scale from 0.1 to 1 based on the averaged number of fatalities per billion passenger-kilometer for the travel mode i (Table 7). By default $s_{i}$ is set to 1 representing a safe journey. $E_{i}$ is proportional to the level of emissions for the travel mode $i$. More precisely, it can be set as the ratio with respect to the minimum level of emissions (set to $E_{i}=1$ ) from the set of travel modes analysed.

Equation (19) is applied to the presented case study with the default settings and based on Tables 4, 6, 7, and 8 giving the results shown in Table 9 considering a working hour cost of $€ 100$. Note that the additional time prior to departure has been set to 20 mins, and 1 and a half hours for the train

Table 9 Travel impact for the route Stockholm-Bordeaux by airplane and train based on objective criteria

\begin{tabular}{llllll}
\hline Travel mode & Emissions & Travel $(€)$ & Safety & Time $(€)$ & $\begin{array}{l}\text { Travel } \\
\text { impact }\end{array}$ \\
\hline Airplane & 6.5 & 65 & 1 & 450 & 2990 \\
Train & 1 & 547 & 1 & 2800 & 3347 \\
\hline
\end{tabular}


and airplane, respectively. This type of assessment being carried out at the booking stage prior to the trip, the delays experienced here are not included.

For this case study example and considering the combined objective criteria of this model, the air journey has the minimum travel impact compared to the train journey revealing the negative impact of a too long journey with respect to the benefit of a minimum environmental impact. This also implies that up to a certain travel distance, the train could be instead the optimal transportation mode.

However how people perceive comfort may differ and will affect the value set on the travel time criterion leading to a more complicated person-dependent problem and therefore different travel impact values. Moreover, the economic aspect of it can also be addressed from a personal perspective.

\subsubsection{Integration of personal value}

In fact, depending on the level and type of comfort needed by a specific person, a journey will be experienced as more or less productive. If that person can spend the travel time efficiently in terms of work or sleep, he or she will have a lower value of travel time (VTT) [49] and the other way around. People negatively affected by a long travel time and having therefore a high demand in comfort to reach a sufficient level of productivity, will have a higher value of travel time. This latter case will also result in a more expensive journey in terms of working hours cost, if the travel time is not minimized. Therefore, the VTT should be personally assessed to define an optimal travel mode choice.

The travel mode can then be further optimized by modelling the personal travel impact (PTI) for every travel mode option $i$, and selecting the travel mode with the smaller PTI as min $\operatorname{PTI}_{i}\left(P V T T_{i}, c_{i}, s_{i}, E_{i}\right)$ for $i \in S$. A simplified model expression is defined based on the personal value of travel time (PVTT) definition [49] as,

$P T I_{i}=\frac{1}{s_{i}}\left(P V T T_{i} E_{i}+\Delta c_{i}\right)$

with $P V T T=\frac{\mu}{\lambda}-\frac{(\delta U / \delta T)}{\lambda}$ and where $U$ is the utility, $T$, is the travel time, and $\mu$ and $\lambda$ are Lagrangian multipliers of the time constraint and of the money budget constraint, respectively, making of the PVTT a difference between two monetary factors [49]. More precisely here, it is the difference between the utility of the travel time or productivity if this time would be spent at the work place and the utility created during the journey thanks to for example electric sockets, internet connection, etc. Moreover, $\Delta c_{i}$ is the difference between the travel cost of option $i$ and a maximum acceptable cost used as a reference for this trip. Since the economic impact of travel costs below the reference cost are negligible, negative values for $\Delta c_{i}$ should be set to zero in order to not affect the PTI and therefore the choice of means of transportation.

Even though the model includes all the variables, it also positions the three variables earlier mentioned, namely time, comfort and environment as having the biggest impact on travel mode decision. In fact the safety coefficient will be most of the time equal to one and the marginal cost equal to zero leading to a more simplified model equation as

$\operatorname{PTI}_{i}=\operatorname{PVTT}_{i} E_{i}$

As an example of application, this latter simplified model, Eq. (21), for travel mode choice is applied to the current study case for different hypothetical personalities and constraints.

- Person A In the first case, the person considers that long trips by train can be very unproductive due to the continuous distractions. Moreover, a high number of connections would just add up more inconvenience. Since the utility created during the journey by train would be

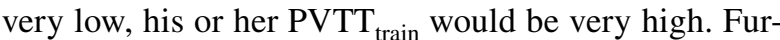
thermore, in this case the access to electric sockets and internet connection would not make any relevant difference in attempting to reduce the PVTT $\mathrm{Prain}_{\text {. }}$ Based on these personal preferences, it is clear that the $\mathrm{PTI}_{\text {train }}$ for person A will be much higher than the $\mathrm{PTI}_{\text {air }}$ despite an emissions coefficient about 6.5 times lower than for the airplane journey. If person A would have a high budget constraint, this would just increase even more the PTI train with a marginal cost bigger than zero. Since for person A, $\mathrm{PTI}_{\text {air }}$ is the lowest, he or she would select the airplane as the optimal travel mode.

- Person B with low budget constraint On the contrary, person $\mathrm{B}$ considers traveling by train to be very productive and also pleasant, due to the presence of electric sockets and Wi-Fi. Person B can have the same level of focus as at the work place and even more due to the lack of interruptions. Despite the 2-day journey required by train, the PVTT $_{\text {train }}$ would be very low, at the same level as or even lower than his or her PVTT ${ }_{\text {air }}$ depending on how travel by airplane is perceived. In any case, $\mathrm{PTI}_{\text {train }}$ would be the lowest due to the lowest emissions coefficient for the train which would be then selected by person B as the optimal choice.

- Person B with high budget constraint In this case, person B has a high marginal cost $\Delta c_{\text {train }}$, increasing the $\mathrm{PTI}_{\text {train }}$ and leading to a new optimal choice, namely the journey by airplane instead of by train.

Note that whereas flying could be an order of magnitude safer than train travel $[46,50]$, Sect. 3.3, fear of flying 


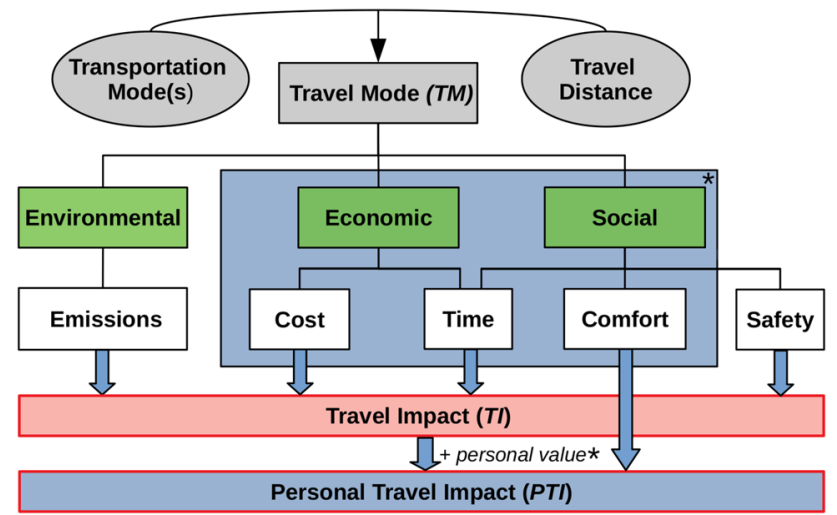

Fig. 10 Illustration of the value model for business travel mode optimization in terms of sustainability

(Aviophobia) [51] is not uncommon and would also increase the PVTT ${ }_{\text {air }}$ since the affected person would not be able to focus on work during the flight.

As a summary, Fig. 10 illustrates the global picture of the presented framework for optimal business travel mode choice from an objective (TI) and personal (PTI) perspective, based on the three pillars of sustainability (environment, economy, and society).

A special focus is then put on the environmental impact and more precisely the transportation modes and their energy generations. In fact, when assessing the transportation modes for optimal travel mode choice, one has to keep in mind, that what makes a particular means of transportation more or less environmental friendly is not the transportation mode itself but the way how the energy is generated as previously shown in Sect. 3.2.3.

\subsection{Energy and power generation}

Electric propulsion and in particular the so-called green electricity [52], appears very attractive. However, it has also been shown in Sect. 3.2.3, the strong impact of the type of electricity generation on $\mathrm{CO}_{2}$ emissions, and which differ by country. For example, whereas some countries may mostly rely on coal power for electricity production such as Germany [53], other may mostly use nuclear power or renewable energies, such as France [54] and Sweden [55], respectively, resulting in significant differences in $\mathrm{CO}_{2}$ emissions per $1 \mathrm{kWh}$ [38], up to a factor of 33 between Germany and Sweden, Fig. 5.

Moreover, KTH travel guidelines [10] state that not only climate effects should be considered but also more generally environmental impact meaning that other forms of emissions than carbon dioxide should be considered.

An attempt has been made to find comparable data for production of electrical energy with burning fuel, such as
Diesel and Jet-A1. Some utilities perform Environmental Product Declarations (EPD) [56] and others provide useful open access information about their energy production. Such information has been used to estimate the environmental impact of different forms of power generation so that some comparison can be made with direct fuel burn and emissions generated for vehicles with combustion engines.

The consequences of electrical power generation per distributed $\mathrm{kWh}$ are compared to fuel burn per generated $\mathrm{kWh}$ energy for propulsion (not energy content of fuel). The results are listed in Table 10. No EPD has been found for conventional oil or gas power plants. For lignite power, the emissions [57] given are for the Niederaussem plant but the fuel use is the average over 5 plants operated by RWE [58]. Grid losses are not considered for electrical power generation. The data presented in Table 10 is most likely rather uncertain, but offers some data for interesting comparisons.

\subsection{Study limitations}

First, there is an important discrepancy in terms of data accuracy between the train and the airplane, making the comparison between transportation modes a complex problem. In fact, the airplane can provide accurate recorded data for a given journey in terms of airplane and flight characteristics, fuel burned, passengers, etc. However, the train analysis is based on estimated data, either from the controllers or from technical data found in the literature for a specific or equivalent train which could also differ in the number of wagons affecting the real energy consumption. Moreover, as already mentioned there is a lack of information regarding the electricity generation source which could be considered in the total energy consumption. The same type of observation applies to the $\mathrm{CO}_{2}$ emissions. Whereas the airplane emissions can directly be computed from real data from the actual flight, $\mathrm{CO}_{2}$ emissions from the train journey rely on the previously mentioned estimated data for energy consumption calculation. In addition to that, the information available on grams of $\mathrm{CO}_{2}$ emissions per $1 \mathrm{kWh}$ of energy generated in a given country is only available for up to year 2016 [38], resulting in a relatively higher level of $\mathrm{gCO}_{2} / \mathrm{kWh}$ compared to 2019 (year of the experienced trip) due to the increase use of renewable energy sources in Europe. New updated data for up to year 2019 have been later on published [38] showing this phenomenon, Fig. 11, and mainly affecting Germany in our study but with no impact on the comparative analysis and conclusions. Moreover, note that the new data only apply to carbon dioxide equivalent $\left(\mathrm{CO}_{2} \mathrm{e}\right)$ emissions which not only include $\mathrm{CO}_{2}$ but also other greenhouse gases effect without any differentiation, and therefore not being appropriate for a direct comparison with the airplane. 
Table 10 Various forms of emissions from generation of 1 kWh energy

\begin{tabular}{|c|c|c|c|c|c|c|}
\hline \multirow{3}{*}{ Energy source } & \multicolumn{4}{|c|}{ Electricity generation } & \multirow{3}{*}{$\begin{array}{l}\text { Turbofan } \\
\text { Sect. 2.1.2 }\end{array}$} & \multirow{3}{*}{$\begin{array}{l}\text { Diesel } \\
\text { Bus [62] }\end{array}$} \\
\hline & Hydro & Wind & Nuclear & Lignite & & \\
\hline & [59] & {$[60]$} & {$[61]$} & {$[57,58]$} & & \\
\hline \multicolumn{7}{|l|}{ Fuel use } \\
\hline Uranium (g) & & & 0.0026 & & & \\
\hline Lignite (g) & & & & 1286 & & \\
\hline JET-A1 (g) & & & & & 340 & \\
\hline Diesel (g) & & & & & & 200 \\
\hline \multicolumn{7}{|l|}{ Emissions } \\
\hline $\mathrm{CO}(\mathrm{g})$ & & 0.15 & & 0.17 & 1.7 & 1.5 \\
\hline $\mathrm{HC}(\mathrm{g})$ & & 0.0017 & 0.0049 & & 0.07 & 0.13 \\
\hline $\mathrm{NO}_{x}(\mathrm{~g})$ & & 0.033 & & 0.61 & 4.2 & 0.4 \\
\hline $\mathrm{CO}_{2}(\mathrm{~g})$ & 10.5 & 17.6 & 6 & 918 & 1082 & 562 \\
\hline $\mathrm{H}_{2} \mathrm{O}(\mathrm{g})$ & & & & & 422 & \\
\hline $\mathrm{SO}_{x}(\mathrm{~g})$ & 0.017 & 0.056 & 0.052 & 0.32 & 0.28 & \\
\hline Spent fuel (g) & & & 0.0028 & & & \\
\hline \multicolumn{7}{|l|}{ Radioactivity } \\
\hline High level (g) & & & $7.5 \times 10^{-9}$ & & & \\
\hline Low level (g) & & & $9.8 \times 10^{-8}$ & & & \\
\hline
\end{tabular}

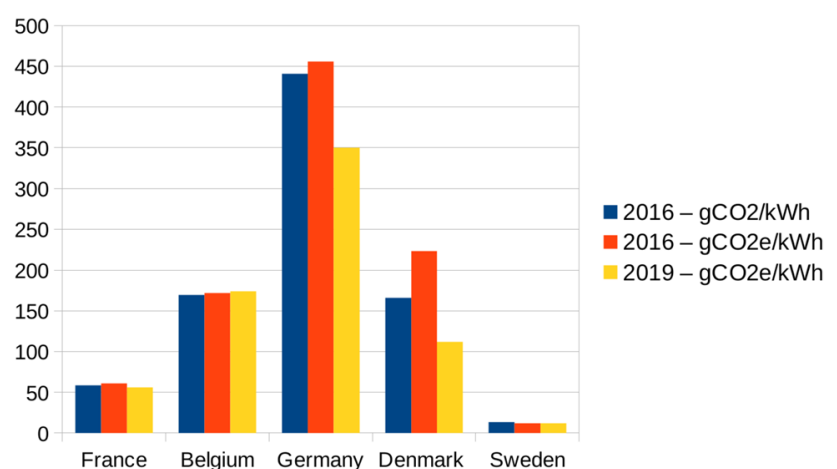

Fig. 11 Comparison for different years of $\mathrm{CO}_{2}$ and $\mathrm{CO}_{2} \mathrm{e}$ emissions per $1 \mathrm{kWh}$ of energy generated at a given country crossed during the train journey [38]

Finally, the analysis is limited to the experienced trip and therefore does not include other travel options, such as indirect flights and night trains. But as already analyzed in other works [7], indirect flights result in a higher level of emissions compared to direct flights. However, the general comparison between transportation modes should remain of the same order.

\section{Conclusion}

The impact of business travel modes has been analyzed and compared for long travel distances from about $2000 \mathrm{~km}$ based on a real trip experienced by airplane and train, in terms of environmental, economic, and social sustainability. It has been shown that there is a clear imbalance between environmental and social sustainability. Actually transport mode efficiency and environmental impact tend to be inversely proportional to each other for long travel distances. Whereas travel by land would imply at least a 2-day journey, travel by air would just require less than half a day and with only few hours spent in transportation modes. In fact, the high number of connections involved in the journey by train, not only resulted in a 2-day journey but also in a high risk for a complete schedule collapse through a domino effect due to cancellations or delays. On the other hand, the environmental impact of this latter was one order of magnitude lower of total $\mathrm{CO}_{2}$ emissions per passenger. This clearly reveals the complexity of the transportation mode choice problem for long-distance travels, contrary to a situation where the most efficient transportation mode would also be one of the most environmentally friendly.

Time and comfort with respect to the environmental impact, have been identified as the most relevant criteria for optimal business travel mode choice, followed by the travel cost and the safety. An attempt to develop a model for business travel mode optimization has led to the definition of an objective function based on the criteria analyzed, namely environment, safety, comfort, time, and cost giving a value of travel impact. The application of this value model to the journey experienced by airplane and train resulted in a minimum travel impact for the journey by air despite an order of magnitude higher of $\mathrm{CO}_{2}$ emissions. This result reveals a serious lack of efficient land 
transportation modes for international travels, despite their low environmental impact. In fact, other land transportation modes, such as car or bus, would result in a longer travel time, increasing therefore the travel impact. However, it can be also concluded that up to a certain travel distance such as $1000 \mathrm{~km}$, the half of the experienced journey, land transportation modes could give the minimum travel impact compared to air transport due to a better balance between environmental impact and efficiency of travel. Travel distance is therefore crucial in identifying the optimal transportation mode.

However, the problem of business travel mode choice is difficult to generalize and should be also perceived from a personal point of view. In fact, how comfort is experienced and therefore travel time is valued is very personal and should be also taken into account as such in the travel time cost. A derived model for travel mode choice has been defined integrating a personal added value, where comfort has been combined to time through the PVTT variable to account for the personal productivity during the journey. This new personalized model would lead to different travel impacts and therefore different optimal travel modes depending on personal preferences and economic constraints.

Concerning the environmental impact, the energy type and also its generation were identified as the core of the problem instead of the transportation mode itself and should be seriously analyzed from its origin. In fact, by theoretically replacing fossil fuel by electricity, the $\mathrm{CO}_{2}$ emissions from the journey by aircraft could be reduced by a factor of 71 with electricity generated in Sweden through hydropower and nuclear power, one order of magnitude lower than with the original journey by train. On the other hand, using electricity generated in Germany which mainly relies on coal power, resulted in a level of $\mathrm{CO}_{2}$ emissions at least twice as high as for the journey by train. However, contrary to the airplane, there is still a significant uncertainty on the train analysis based on general technical data with no data recorded during the journey necessary for an accurate computation of the energy consumption and thus emissions.

Finally, other aspects within the environmental impact should be considered, such as the energy consumption at the airport and train stations, but also external noise, materials and infrastructures more favorable for the airplane case.

Acknowledgements This research was funded by the Centre for Sustainable Aviation (CSA) at KTH Royal Institute of Technology, Stockholm, Sweden in cooperation with the Swedish Transport Administration, Trafikverket.

Funding Open access funding provided by Royal Institute of Technology.

\section{Declarations}

Conflicts of interest The authors declare that they have no conflict of interest.

Open Access This article is licensed under a Creative Commons Attribution 4.0 International License, which permits use, sharing, adaptation, distribution and reproduction in any medium or format, as long as you give appropriate credit to the original author(s) and the source, provide a link to the Creative Commons licence, and indicate if changes were made. The images or other third party material in this article are included in the article's Creative Commons licence, unless indicated otherwise in a credit line to the material. If material is not included in the article's Creative Commons licence and your intended use is not permitted by statutory regulation or exceeds the permitted use, you will need to obtain permission directly from the copyright holder. To view a copy of this licence, visit http://creativecommons.org/licenses/by/4.0/.

\section{References}

1. FAA. Aviation emissions, impacts \& mitigation: a primer, Office of Environment and Energy. Technical report (2015)

2. Fleuti, E., Maraini, S.: Advanced aircraft emission modeling, environment-services. Zurich-Airport, Technical report (2014)

3. Filippone, A.: Analysis of carbon-dioxide emissions from transport aircraft. J. Aircr. 45(1), 185-198 (2008)

4. Jardine, C.N.: Calculating the environmental impact of aviation emissions. Technical report, Oxford University Centre for the Environment (2005)

5. Engineering National Academies of Sciences and Medicine. Electric propulsion. In: Commercial Aircraft Propulsion and Energy Systems Research: Reducing Global Carbon Emissions, chapter 4, pp. 51-108. Washington, DC: The National Academies Press (2016)

6. Arsenault, J., Talbot, J., Boustani, L., Gonzalès, R., Manaugh, K.: The environmental footprint of academic and student mobility in a large research-Oriented University. Environ. Res. Lett. 14, 095001 (2019)

7. Ciers, J., Mandic, A., Toth, L.D., Veld, G.O.: Carbon footprint of academic air travel: a case study in Switzerland. Sustainability 11, 80 (2018)

8. van Ewijk, S., Hoekman, P.: Emission reduction potentials for academic conference travel. J. Ind. Ecol. 25, 1-11 (2020)

9. Karlsson, S.: Inrättande av Klimatpott i Syfte att Minska KTH:s Koldioxidutsläpp. Kungliga Tekniska högskolan, http://www.kth. se, Stockholm, Sweden (2018). Accessed 2018

10. Ousi, M.: Guidelines for Meetings and Travel. Kungliga Tekniska högskolan, http://www.kth.se, Stockholm, Sweden (2018). Accessed 2018

11. United Nations General Assembly. Resolution adopted by the general assembly on 16 September 2005. 60/1. 2005 World Summit Outcome. Technical Report 05-48760 (2005)

12. DuBois, D., Paynter, G.C.: Fuel flow method 2 for estimating aircraft emissions. Technical Report SAE Technical Paper Series 2006-01-1987, Society of Automotive Engineers, Washington, DC (2006)

13. Johansson, B.: Mätning av bullerappen-sammanställning. Arbetsmiljöverket, http://www.av.se, Stockholm, Sweden (2017). Accessed 2018

14. Wang, L.: Energy efficiency for diesel passenger trains. Master's thesis (2014)

15. Peckham, C.: Improving efficiency of traction energy use. Technical Report T618, RSSB (2007) 
16. Karlsson, S., Kushnir, D.: How energy efficient is electrified transport? In: Sandén B (ed.) System Perspectives on Electromobility. Chalmers University of Technology (2013)

17. Flightradar24 Global Flight Tracking Service. (2018). http://www. flightradar24.com/

18. Anderson, J.D.: Aircraft Performance and Design. McGraw-Hill, New York (1999)

19. Etkin, B., Reid, L.D.: Dynamics of Flight, Stability and Control. Wiley, Hoboken (1996)

20. Obert, E.: Aerodynamic Design of Transport Aircraft. Ios Press, Amsterdam (2009)

21. Kim, B., Fleming, G., Balasubramanian, S., Malwitz, A., Lee, J., Ruggiero, J., Waitz, I., Klima, K., Stouffer, V., Long, D., Kostiuk, P., Locke, M., Holsclaw, C., Morales, A., McQueen, E., Gillette, W.: SAGE technical manual, version 1.5. Technical Report FAAEE-2005-01 (2005)

22. Hadaller, O.J., Momenthy, A.M.: The characteristics of future fuels. Technical Report Boeing publication D6-54940 (1989)

23. DuBois, D., Paynter, G.C.: Fuel flow method 2 for estimating aircraft emissions. Technical Report SAE Technical Paper Series 2006-01-1987, Washington, DC (2006)

24. Jacobsen, M., Ringertz, U.: Reducing emissions using aircraft trajectory optimization. Internal report, TRITA/AVE 2009:43, Department of Aeronautical and Vehicle Engineering, KTH (2008)

25. Nuic, A., Poinsot, C., Iagaru, M., Gallo, E., Navarro, F.A., Querejeta, C.: Advanced aircraft performance modeling for ATM: enhancements to the BADA model. In: 24th Digital Avionics System Conference (DASC), Washington, D.C., USA, Vol 1, pp 2.B.4-2.B.4 (2005)

26. Eurocontrol. User manual for the base of aircraft data (BADA) revision 3.6. Technical Report EEC Note No. 10/04 (2004)

27. ICAO Aircraft Engine Emissions Databank. http://www.caa.co. uk/ (2009)

28. Wey, C.C., Anderson, B.E., Hudgins, C., Wey, C., Li-Jones, X., Winstead, E., Thornhill, L.K., Lobo, P., Hagen, D., Whitefield, P., Yelvington, P.E., Herndon, S.C., Onasch, T.B., Miake-Lye, R.C., Wormhoudt, J., Knighton, W.B., Howard, R., Bryant, D., Corporan, E., Moses, C., Holve, D., Dodds, W.: Aircraft particle emissions experiment (APEX). NASA/TM 2006-214382. September (2006)

29. Schaefer, M., Bartosch, S.: Overview on fuel flow correlation methods for the calculation of NOx , CO and HC emissions and their implementation into aircraft performance software. Technical Report Technical Report, DLR (2013)

30. Andersson, E., Lukaszewicz, P.: Energy consumption and related air pollution for scandinavian electric passenger trains. Technical report, Kungliga Tekniska högskolan, Stockholm (2006)

31. Schach, R., Naumann, R.: Comparison of high-speed transportation systems in special consideration of investment costs. J. Transport 22(3), 139-147 (2007)

32. Lindgreen, E., Sorenson, S.C.: Simulation of energy consumption and emissions from rail traffic. Technical report, Danmarks Tekniska Högskola (2005)

33. Fidansoy, Y.: Examining the load peaks in high-speed railway transport. In: DEMAND Centre Conference, Lancaster, 13-15 April 2016. http://www.demand.ac.uk/demand-confe rence-2016-papers/

34. Lukaszewicz, P., Andersson, E.: Green train energy consumption: estimations on high-speed rail operations. Technical Report ISBN 978-91-7415-257-9, Royal Institute of Technology (KTH) (2009)

35. Push-Pull Trainset Germany. https://www.skoda.cz/en/references/ push-pull-souprava-nemecko/?from=prod (2020). Accessed 2020

36. ICE 4 (Deutsche Bahn). https://en.wikipedia.org/wiki/ICE_4_ (Deutsche_Bahn)(2020). Accessed 2020
37. Mercedes-Benz Citaro O530G (2005) euro 5. https://www.womy. com/used-buses/mercedes-citaro-0530g/ (2005). Accessed 2020

38. Overview of Electricity Production and Use in Europe. https:// www.eea.europa.eu/data-and-maps/indicators/overview-of-theelectricity-production-2/assessment-4 (2019). Accessed 2019

39. PREN 50591. Specification and Verification of Energy Consumption for Railway Rolling Stock (2018)

40. BEIS. 2017 Government GHG conversion factors for company reporting: methodology paper for emission factors: final report. Technical Report Department for Business, Energy \& Industrial Strategy (BEIS) (2017)

41. Jacobsen, M.: On improving efficiency of flight using optimization. PhD thesis, Royal Institute of Technology (2009)

42. ICAO Carbon Emissions Calculator. http://www.icao.int/envir onmental-protection/CarbonOffset/Pages/default.aspx (2016). Accessed 2020

43. Jardine, C.N.: Calculating the carbon dioxide emissions of flights. Technical report, Oxford University Centre for the Environment (2009)

44. Nordic Energy Research: Progress towards Nordic Carbon Neutrality. Tracking Nordic Clean Energy Progress, Technical report (2019)

45. Our Trains, SJ AB. https://www.sj.se/en/about/about-sj/our-trains. html (2020)

46. Aviation Safety. https://en.wikipedia.org/wiki/Aviation_safety (2019). Accessed 2019

47. National Aeronautics and Space Administration. Space shuttle era facts. Technical Report FS-2011-7-142-KSC (2011)

48. List of Space Shuttle crews. https://en.wikipedia.org/wiki/List of_Space_Shuttle_crews (2020). Accessed 2020

49. Marco, K., de Jong, G.: Value of travel time as a function of comfort. J. Choice Model. 28, 97-107 (2018)

50. European Union Agency for Railways. Railway safety in the European Union: safety overview 2017. Technical report (2017)

51. Clark, G., Rock, A.: Processes contributing to the maintenance of flying phobia: a narrative review. Front. Psychol. 7, 754 (2016)

52. Doble, M., Kruthiventi, A.K.: Alternate energy sources. In: Green Chemistry and Engineering, chapter 7, pp. 171-192. Academic Press (2007)

53. Burger, B.: Power generation in Germany-Assessment of 2017. Technical report, Fraunhofer Institute for Solar Energy Systems ISE (2018)

54. World Nuclear Association. Nuclear Power in France. https:// www.world-nuclear.org/information-library/country-profiles/ countries-a-f/france.aspx (2019). Accessed 2020

55. Swedish Energy Agency. Energy in Sweden 2019: an overview. Technical report (2019)

56. Environmental Product Declaration (EPD). https://www.envir ondec.com/What-is-an-EPD/. Accessed 2020

57. Umweltbundesamt Deutschland. Emissions from RWE Power AG Kraftwerk Niederaussem (2016)

58. RWE Power AG. Niederaussem Power Plant. kraftwerk-niederaussem-englisch-download.pdf (2018)

59. Vattenfall AB. EPD of Electricity from Vattenfall's Nordic Hydropower. EPD registration S-P-00088 (2018)

60. Vattenfall, AB.: Certified Environmental Product Declaration EPD of Electricity from Vattenfall's Nordic Wind Farms. EPD registration S-P-00183 (2016)

61. Vattenfall, AB.: Certified Environmental Product Declaration EPD of Electricity from Vattenfall Nordic Nuclear Power Plants. EPD registration S-P-00923 (2016)

62. EU: Heavy-Duty Truck and Bus Engines. https://www.dieselnet. com/standards/eu/hd.php (2019). Accessed 2019 